Resenha de artigo

Article view

\title{
Exercício físico e CoViD-19 - o papel do exercício físico em favor da saúde e da recuperação: resenha apresentando o trabalho de Silveira et al.
}

\section{Physical Exercise and Covid-19 - The Role of Physical Exercise for Health and Recovery: An Article View Presenting the work of Silveira et al.}

\section{Corpo Editorial REF/JPE}

Recebido em: 29 de dezembro de 2020. Aceito em: 30 de dezembro de 2020.

Publicado online em: 30 de dezembro de 2020.

DOI: $10.37310 /$ ref.v89i3.2716

\section{Resumo}

Introdução: Como parte da Edição Especial de 2020 I, a Revista de Educação Física / Journal of Physical Education (REF/JPE) está trazendo aspectos científicos da prática de atividade física relacionados à pandemia de CoViD-19.

Objetivo: Apresentar e indicar aos leitores da REF/JPE, a leitura da revisão integrativa de Silveira et al., publicado no periódico Clinical and Experimental Medicine, quanto aos benefícios do exercício físico sobre o funcionamento do sistema imunológico e sua relação com a prevenção e a recuperação da CoViD-19.

Conclusão: De acordo com a literatura, o exercício físico atua sobre o sistema de defesa do organismo favorecendo a resposta a doenças virais. Nesse contexto, a prática regular de atividade física, em intensidade adequada, está indicada como estratégia de prevenção para CoViD-19, face ao fortalecimento e à preparação do sistema imunológico para enfrentar o vírus.

Palavras-chave: exercício físico, pandemia, coronavírus, imunologia, prevenção de doenças

\section{Abstract}

Introduction: As part of the Special Edition 2020 I, the Revista de Educação Física / Journal of Physical Education (REF/JPE)

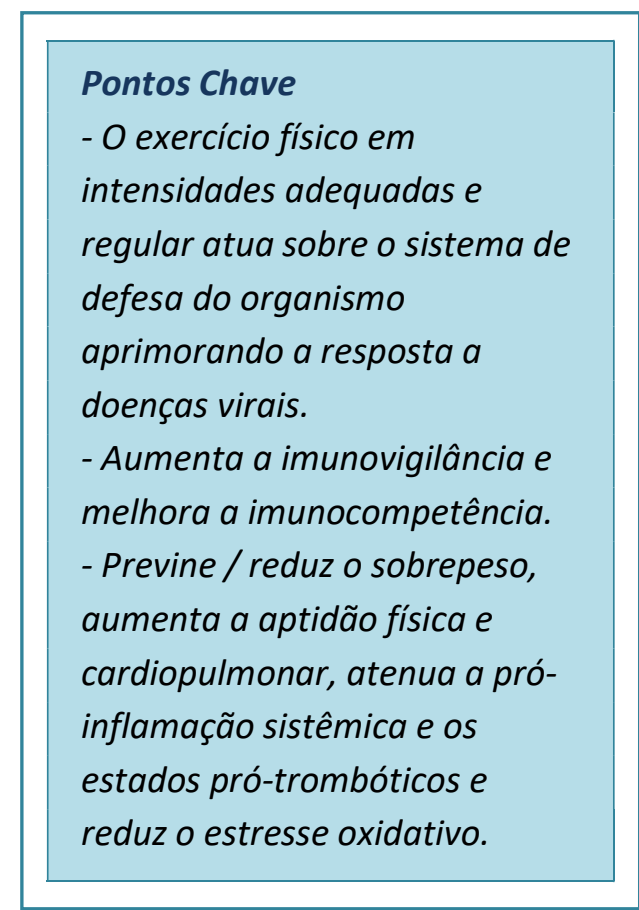

brings scientific aspects of the practice of physical activity related to the CoViD-19 pandemic.

Objective: To indicate to the REF/JPE public, the reading of the integrative review by Zadow et al., published in Clinical and Experimental Medicine journal, regarding the benefits of physical exercise for immune system functioning and its relationship with prevention and recovery of CoViD-19.

Conclusion: According to the literature, physical exercise acts on the body's defense system favoring the response to viral diseases. In this context, the regular practice of physical activity at adequate intensity is indicated as a prevention strategy in coping with CoViD-19 by strengthening and preparation of the immune system to better tackle the coronavirus.

Keywords: exercise, pandemic, coronavirus, immunology, disease prevention.

$\S$ Autor correspondente: Corpo Editorial REF/JPE e e-mail: revistaef.ccfex@gmail.com Afiliações: ${ }^{1}$ Centro de Capacitação Física do Exército (CCFEx), Rio de Janeiro - RJ, Brasil. 


\section{Exercício físico e CoViD-19 - o papel do exercício físico em favor da saúde e da recuperação: resenha apresentando o artigo de Silveira et al.}

\section{Introdução}

O início do ano de 2020 foi marcado pela ocorrência de uma pandemia de uma nova doença: a SARS-CoV2 (Severe Acute Respiratory Syndrome: síndrome respiratória aguda severa, causada por um novo coronavírus, o CoV2). A doença foi assim denominada porque, em 2002, o mundo já havia conhecido a pandemia causada por um coronavírus a SARS-CoV, que teve origem em Guandong, na China(1). Em dezembro de 2019, desta vez na província de Wuhan (China), registrou-se o primeiro caso de infecção pelo Cov2(2). O vírus também causa SARS, porém, apresenta diversas outras características distintas, em comparação com o vírus anterior(3). Assim, a nova doença ficou conhecida como CoViD-19 (Corona Virus Disease from 2019).

Como parte da Edição Especial de 2020 parte I, a Revista de Educação Física / Journal of Physical Education (REF/JPE) está trazendo aspectos científicos da prática de atividade física relacionada à pandemia.

$\mathrm{O}$ objetivo do presente trabalho foi apresentar e indicar aos leitores da REF/JPE, a leitura da revisão integrativa de Silveira et al.(4), publicado em setembro de 2020, no periódico internacional Clinical and Experimental Medicine.

\section{Desenvolvimento}

$\mathrm{O}$ artigo intitulado "Physical Exercise as a tool to help the immune system against CoViD19: an integrative review" de Silveira et al.(4). O estudo de revisão integrativa teve por objetivo examinar os benefícios do exercício físico sobre o funcionamento do sistema imunológico e sua relação com a prevenção e

\footnotetext{
${ }^{11}$ Citocinas: são polipeptídeos ou glicoproteínas extracelulares, hidrossolúveis que podem ser próinflamatórias ou anti-inflamatórias. As citocinas são necessárias para a resposta inflamatória, favorecendo a cicatrização de uma lesão tecidual, entretanto, uma produção altamente elevada de citocinas pró-inflamatórias pode se
}

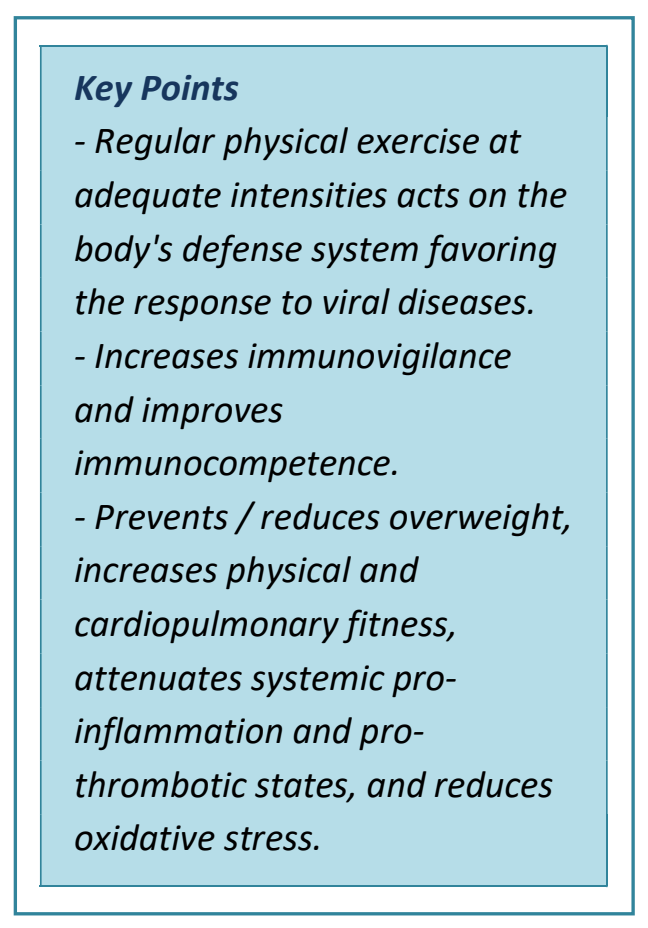

a recuperação da CoViD-19, presentes na literatura, tendo focalizado os seguintes temas:

* Influência do exercício físico na resposta imunológica

O exercício físico, tanto agudo quanto crônico, alteram o sistema imunológico, cujos efeitos são modulados por regularidade, intensidade e duração do esforço(5). De acordo com o exibido na literatura, os autores apontam que exercícios físicos praticados em intensidade moderada estimulam a imunidade celular. Por outro lado, exercícios prolongados ou de alta intensidade, sem o tempo de recuperação apropriado, diminuem essa imunidade e aumentando a propensão para doenças infecciosas.

Efeitos do exercício físico sobre os componentes do sistema imunológico

$>$ Citocinas $^{1}$

manifestar sistemicamente com instabilidade hemodinâmica ou distúrbios metabólicos. As citocinas podem ser reconhecidas por neurônios e utilizadas para desencadear diversas reações celulares que influenciam na atividade, proliferação e sobrevida da célula imunológica(6,7). 
$>$ Neutrófilos ${ }^{2}$

$>$ Leucócitos ${ }^{3}$;

$>$ Células apresentadoras de antígenos ${ }^{4}$;

$>$ Células exterminadoras naturais, também chamadas de natural killers $(\mathrm{NK})^{5}$; e

$>$ Linfócitos $^{3}$.

* Virologia da CoViD-19

* A resposta imunológica a infecções por coronavírus

* Respostas imunológicas desequilibradas na CoViD-19

Tempestade de citocinas;

> Alterações nas contagens celulares;

$>$ Desordens coagulativas - Essas alterações fisiológicas em resposta ao vírus invasor podem levar a desordens coagulativas: tromboembolismo venoso e coagulação intravascular disseminada. Os autores(5) explicam que a coagulação sanguínea é o mecanismo mais rápido para confinar e inativar infecções, sendo que é a primeira e a última linha de defesa inata do sistema imune. Quando ocorre uma hiperativação desse sistema, a coagulação pode se tornar intravascular e disseminada, causando falência múltipla em diversos órgãos, eventos associados aos desfechos negativos da CoViD-19.

\footnotetext{
${ }^{2}$ Neutrófilos: são os glóbulos brancos mais abundantes no organismo humano e constituem a linha de frente de defesa em resposta a micróbios invasores, por fagocitose de patógenos e / ou liberação de fatores antimicrobianos contidos em grânulos especializados.

${ }^{3}$ Leucócitos: são os glóbulos brancos, agentes de defesa do organismo humano desempenhando múltiplos papéis. São produzidos na medula óssea, à exceção dos linfócitos que são produzidos no tecido linfático. Dividem-se em dois grandes grupos: a) Granulócitos (fagócitos): basófilos, eosinófilos, neutrófilos, mastócitos, monócitos, macrófagos, células dendríticas e células natural killers; e b) Grupo dos agranulócitos - os linfócitos,: linfócitos $B$ e linfócitos $T$, que desempenham função chave tanto na imunidade inata quanto na imunidade adaptativa(8).
}

* Condições do paciente pré CoViD-19 Neste tópico, os autores apresentaram os seguintes temas:

$>$ Envelhecimento;

$>$ Obesidade;

$>$ Diabetes tipo II; e

$>$ Síndrome metabólica.

\section{* Exercício físico e CoViD-19}

Exercícios dinâmicos, que geram sobrecarga cardiorrespiratória, promovem a mobilização e redistribuição de linfócitos efetores, intermediada pelas catecolaminas - que, primariamente, estimulam subtipos de linfócitos que têm a capacidade de migrar dos reservatórios (vasos sanguíneos, baço e medula óssea) para os tecidos linfáticos e órgãos (como o trato respiratório, pulmões e intestinos). Todos esses eventos têm por objetivo aumentar a vigilância imunológica e aprimorar a resposta antiviral(4,11). Nesse contexto, a literatura mostra que a prática regular de atividade física, em intensidade moderada, promove a atividade anti-patógenos por parte dos magrófagos e, ao mesmo tempo, aumenta a circulação de células imunes, imunoglobulinas e citocinas antiinflamatórias. Assim sendo, reduz a carga patogênica, diminuindo o risco de danos pulmonares resultantes do influxo de células inflamatórias.

$>$ Exercício físico regular em intensidade moderada está diretamente associado a:

- Diminuição de mortalidade por pneumonia;

\footnotetext{
${ }^{4}$ Células apresentadoras de antígenos: são assim chamadas as células dendríticas, células $B$ e macrófagos, constituindo um grupo em que os três tipos de células podem apresentar antígenos para reestimular a memória ou linfócitos $T$ efetores $(9,10)$.

${ }^{5}$ Natural killer cells (NK): as células exterminadoras naturais são linfócitos são leucócitos da mesma família das células T e $B$, provenientes de um progenitor comum. No entanto, como células do sistema imune inato, as células NK são classificadas como linfócitos inatos do grupo I (ILCS) e respondem rapidamente a uma ampla variedade de desafios patológicos. As células NK são mais conhecidas por matar células infectadas por vírus e por detectar e controlar os primeiros sinais de câncer.
} 
- Diminuição de mortalidade por influenza;

- Melhora na função cardiorrespiratória;

- Melhora na resposta a vacinas;

- Melhora na resposta a agentes patógenos infecciosos;

- Melhora no metabolismo da glicose;

- Melhora no metabolismo dos lipídios; e

- Melhora no metabolismo da insulina.

\section{Conclusão}

Os autores(4) concluíram que ainda há lacunas no conhecimento a respeito dos mecanismos patológicos envolvidos na CoViD-19.

Quanto aos benefícios do exercício físico regular, os autores apontaram que a prática em intensidade adequada aumenta a vigilância imunológica e melhora a competência do sistema imune. Isso resulta em um melhor controle a patógenos, com destaque para a necessidade desse aprimoramento para os idosos, devido à sua maior susceptibilidade à infecção severa à CoViD-19.

Outros benefícios do exercício no formato de prescrição citado, referem-se ao estado do paciente pré CoViD-19, pois, favorece a prevenção/redução de sobrepeso, aumento da aptidão física e cardiorrespiratória, diminuição da inflamação sistêmica e de estados pró trombóticos, diminuição do estresse oxidativo, melhora nos metabolismos de glicose, insulina e lipídios, além de favorecer a resposta do organismo à vacina.

Os autores discutiram, ainda, que para além dos cuidados higiênicos, que incluem uso de equipamentos de proteção individual (EPIs), estão recomendadas ações para imprimir um estilo de vida saudável, minimizar fatores estressores e fortalecer o sistema imunológico, como é o caso da prática regular de atividade física. Confiram esse importante e abrangente trabalho de Silveira et al.(4).



Figura 1 - Silveira et al.(4). disponível em: doi:10.1007/s10238-020-00650-3

\section{Declaração de conflito de interesses}

Não há nenhum conflito de interesses no presente estudo.

\section{Declaração de financiamento}

Estudo conduzido sem financiamento.

\section{Referências}

1. Stadler K, Masignani V, Eickmann M, Becker S, Abrignani S, Klenk H-D, et al. SARS--beginning to understand a new virus. Nature Reviews. Microbiology. [Online] 2003;1(3): 209-218. Available from: doi:10.1038/nrmicro 775

2. Huang C, Wang Y, Li X, Ren L, Zhao J, $\mathrm{Hu} \mathrm{Y}$, et al. Clinical features of patients infected with 2019 novel coronavirus in Wuhan, China. Lancet (London, England). [Online] 2020;395(10223): 497-506. Available from: doi:10.1016/S0140-6736(20)30183-5

3. Liu S-L, Saif L. Emerging Viruses without Borders: The Wuhan Coronavirus. Viruses. [Online] 
2020;12(2). Available from:

doi:10.3390/v12020130

4. da Silveira MP, da Silva Fagundes KK, Bizuti MR, Starck É, Rossi RC, de Resende e Silva DT. Physical exercise as a tool to help the immune system against COVID-19: an integrative review of the current literature. Clinical and Experimental Medicine. [Online] 2020; Available from: doi:10.1007/s10238-02000650-3 [Accessed: 10th December 2020]

5. Zadow EK, Wundersitz DWT, Hughes DL, Adams MJ, Kingsley MIC, Blacklock HA, et al. Coronavirus (COVID-19), Coagulation, and Exercise: Interactions That May Influence Health Outcomes. Seminars in Thrombosis and Hemostasis. [Online] 2020;46(7): 807-814. Available from: doi:10.1055/s-0040-1715094

6. Oliveira CMB de, Sakata RK, Issy AM, Gerola LR, Salomão R. Citocinas e dor. Revista Brasileira de Anestesiologia. [Online] Sociedade Brasileira de Anestesiologia; 2011;61(2): 260-265. Available from: doi:10.1590/S003470942011000200014

7. Curfs JH, Meis JF, Hoogkamp-Korstanje JA. A primer on cytokines: sources, receptors, effects, and inducers. Clinical Microbiology Reviews. 1997;10(4): 742780.

8. David S, David H, Craig H, Sally H. Vida: A Ciência da Biologia - Vol III 11.ed.: Forma e Função de Plantas e Animais. Artmed Editora; 546 p.

9. Stagg AJ, Knight SC. Antigen-presenting Cells. eLS. [Online] American Cancer Society; 2001. Available from: doi:10.1038/npg.els.0000903 [Accessed: 15th January 2021]

10. Vanguri VK. The Adaptive Immune System. In: McManus LM, Mitchell RN (eds.) Pathobiology of Human Disease. [Online] San Diego: Academic Press; 2014. p. 1-4. Available from:
doi:10.1016/B978-0-12-386456-7.011011 [Accessed: 15th January 2021]

11. Simpson RJ, Katsanis E. The immunological case for staying active during the COVID-19 pandemic. Brain, Behavior, and Immunity. [Online] 2020;87: 6-7. Available from: doi:10.1016/j.bbi.2020.04.041 